\title{
(Des)Integraciones posbélicas. Lo experimental situacionista frente al reformismo del Nouveau Roman
}

\author{
Elena PoLo FernÁNDEZ \\ Universidad Complutense de Madrid \\ poloelena@hotmail.com
}

\begin{abstract}
RESUMEN
A partir de 1945, con el fin de la Segunda Guerra Mundial, el arte considerado hasta el momento de vanguardia es asimilado por una cultura de masas que poco a poco está ganando terreno en las inauguradas democracias occidentales. En Francia el dadaísmo y el surrealismo son acogidos y celebrados por las grandes masas urbanas de tal manera que esa posición marginal y revolucionaria que ocupaban antes de la guerra queda ahora desplazada. Pasan de la periferia al centro de la cultura y dejan un vacío que rápidamente será disputado por distintos movimientos como el letrismo, el grupo CoBrA, el situacionismo o los nouveaux, los cuales propondrán nuevas y muy diferentes aproximaciones a la práctica artística.
\end{abstract}

Palabras clave: Posguerra, Francia, vanguardias artísticas, situacionismo, Nouveau Roman.

\section{Post-conflict (Des)Integratins. Situationist Experimentalism against the Reformism of the Noveau Roman}

\begin{abstract}
Since 1945, after the end of the Second World War, the art considered so far as a vanguard is assimilated by the mass culture that is gradually gaining ground in the new Western democracies. In France, Dadaism and Surrealism are welcomed and celebrated by the great urban mass in a way that the marginal and revolutionary position they had before the war is now displaced. They move from the periphery to the centre of the culture, and they leave a gap that will be quickly contested by different movements, such as Lettrism, the CoBrA group, Situationism, or Nouveaux. They will propose new and very different approaches to art.
\end{abstract}

Keywords: Postwar Period, France, Art Vanguards, Situationism, Nouveau Roman. 


\section{1. (Re)generación de las vanguardias en Francia}

Es innegable que, aunque los movimientos artísticos se suceden sin interrupción, la Segunda Guerra Mundial supone un quiebro en el rumbo que el arte había tomado durante la primera posguerra. La capital del arte se desplaza de París a Nueva York cuando los Estados Unidos se convierten en centro hegemónico de irradiación cultural. No obstante, Francia, donde queremos poner la mirada, sigue siendo uno de los principales escenarios de reunión artística donde surgen algunos de los cuestionamientos más interesantes sobre los principios estéticos que rigen la cultura occidental. Allí la guerra, que representa un golpe moral para la conciencia europea, provoca en los sectores intelectuales más comprometidos el descrédito hacia la trascendencia del arte y un alejamiento de las orientaciones artísticas dominantes, especialmente hacia el espíritu y las dinámicas de la vanguardia histórica (cuya decadencia había comenzado en el periodo de entreguerras) no solo en su concepción estética, sino también ética y política. La estética visual dadaísta y, sobre todo, la surrealista son ahora empleadas por la cultura de masas para la producción de todo tipo de mercancías al servicio del capital, especialmente en el terreno del diseño, la moda y la publicidad. Además, el hecho de que este arte de vanguardia «degenerado» (así lo apellidaban los nazis alemanes) fuera perseguido por los totalitarismos, mirado con recelo por la Unión Soviética desde mediados de los años 20 y prohibido ya en los años 30 por los países comunistas - por ser considerado como una manifestación pequeño-burguesa del capitalismo- provoca que a partir de la segunda mitad de los años 40, Estados Unidos lo adopte como su arte oficial principalmente a través de la llamada Escuela de Nueva York formada por la joven generación de pintores del Expresionismo Abstracto. Este acontecimiento supuso la institucionalización o asimilación social de la vanguardia, lo cual es, precisamente, el único elemento al que no puede resistir; automáticamente pierde su razón de ser y se vacía de contenido: lo revolucionario se convierte en académico ${ }^{1}$.

Como reacción a esto nace una serie de grupos en distintos países del bloque capitalista que tratan de desterrar los viejos movimientos vanguardistas y de generar un arte y unas formas de vida acordes a la realidad presente y a las exigencias políticas del momento. Estos grupos pretenden conquistar el lugar revolucionario y originalmente marginal que ocupó la vanguardia prebélica y abogan por una inversión radical del concepto «arte»: el letrismo, el Grupo Surrealista Revolucionario, Reflex, CoBrA o la Internacional Letrista son algunos de los ejemplos. Muchos de sus miembros confluirán en la Internacional Situacionista que funcionará como síntesis de los anteriores al recoger gran parte de sus propuestas. De aquí en adelante

${ }^{1}$ Frances Stonor Saunders en La CIA y la guerra fría cultural afirma: «De lo que no hay duda es de que la CIA encontró una oportunidad ideológica en el expresionismo abstracto y de que por eso lo promovió. Es irónico, por no decir algo más fuerte, que la vanguardia americana de posguerra, muchos de cuyos representantes eran teórica o activamente simpatizantes de la izquierda, terminara siendo la niña mimada del capitalismo burgués y que sus cuadros acabaran colgados en los vestíbulos de los bancos e incluso en las paredes de la sede de la CIA en Langley». 
nos ocuparemos de rastrear las aportaciones más relevantes de estos grupos neovanguardistas, hoy prácticamente olvidados por la academia, en especial de los situacionistas, y fijaremos nuestra atención en su intento de definirse por contraste con otros movimientos como el Nouveau Roman.

\section{Los gérmenes del situacionismo}

El primero que retoma el experimentalismo y la radicalidad de las primeras vanguardias es el letrismo, fundado por Isidore Isou y Gabriel Pomerand en París en 1946. Recogen la herencia iconoclasta de los dadaístas y de los primeros surrealistas y proponen la destrucción de las formas artísticas iniciadas por Baudelaire reduciendo la poesía a su elemento último, la letra. Un año después de su creación la prestigiosa Gallimard publica el manifiesto letrista de Isou, Introduction à une Nouvelle Poésie et à une Nouvelle Musique. Para Isou la nueva poesía ha de fundarse en la deconstrucción de las palabras en sus elementos mínimos constituyentes: las letras, como representación gráfica, y su articulación sonora, los fonemas. Propone abolir los vocablos y para ello renuncia a su uso reemplazándolos por una poética de sonidos basada en juegos onomatopéyicos y en una atención particular a la sonoridad de las letras. Ambiciona fusionar la lírica y la música en un arte único.

En el letrismo aparece un rasgo muy importante que se repetirá en otras corrientes artísticas de vanguardia: buscan la innovación radical no solo en el arte, sino en todas las disciplinas de la vida y del saber. A pesar de sus presupuestos radicales, para Stewart Home no llegaron a la raíz del orden establecido:

Los letristas nunca entendieron que el arte, a diferencia de la expresión, es una construcción burguesa y aunque se enorgullecían de haber expulsado a los surrealistas de su trono, no fueron capaces de construir nada a partir de los descubrimientos del Dadá berlinés. (Home 2004: 56)

Sin embargo, Anselm Jappe les concede mayor mérito al afirmar que se debe a ellos el concepto de détournement, 'desviación', 'tergiversación', que luego desarrollan los situacionistas. Se trata de una técnica de reciclaje que deriva, por un lado, del collage dadaísta y, por otro, de las citas deformadas que empleaban Marx y Lautréamont ${ }^{2}$. Consiste en tomar algún objeto creado por el capitalismo, distorsionar su significado y uso original para producir un efecto crítico.

${ }^{2}$ Lautréamont, quien afirmaba «el plagio es necesario, el progreso lo implica», empleó esté método de desviación al lenguaje teórico en Poésies donde reciclaba máximas de otros autores. Asimismo, Maurice Viroux sostiene que Los cantos de Maldolor son una tergiversación de Buffon y de otras obras de historia natural. Por otra parte, Feuerbach y Marx popularizaron un estilo lingüístico para sus obras teóricas cercano al quiasmo que consistía en la inversión del genitivo dando como resultado sintagmas del tipo «filosofía de la miseria/miseria de la filosofía». 
Un año después de la formación del Movimiento Letrista, en 1947, Christian Dotremont, miembro del grupo surrealista belga, promueve la formación del Grupo Surrealista Revolucionario en respuesta al distanciamiento de la vida política por el que optó Breton tras la Segunda Guerra Mundial. En la primera reunión en Bruselas sus miembros se proponen renovar la experimentación surrealista desde la acción colectiva y en el contexto de la vida cotidiana. Este parámetro de la cotidianidad - que proviene de la recién publicada Crítica de la vida cotidiana de Henry Lefebvre, surrealista en su juventud- será fundamental más adelante en otros grupos, especialmente los situacionistas. Para Lefebvre lo cotidiano es un embalse subterráneo en el cual se sedimentan los convenios y las mentiras del poder. Esta cotidianidad supone una barrera para liberar la fantasía y encontrar la propia expresión, la autonomía del ser. Por esta razón, el arte desempeña un papel fundamental en la sociedad como medio de experiencia capaz de demostrar lo infundado del convencionalismo de la vida cotidiana.

En Holanda Constant funda un año más tarde, 1948, el grupo experimental Reflex junto a los pintores Karel Appel y Corneille. Ese mismo año estos tres pintores se encuentran con Dotremont y Asger Jorn (figura central del grupo artístico danés Host) en París en un congreso organizado por el Centro Internacional para la Documentación del Arte de Vanguardia. Les une el enfado por el tono complaciente del debate, que terminan abandonando para reunirse en el café del Quai St. Michel donde dan forma a un nuevo grupo: $\mathrm{CoBrA}$, acrónimo de Copenhague, Bruselas y Ámsterdam, sus ciudades de procedencia. En el manifiesto, redactado por Constant, se aboga por un arte nuevo y se invita a los artistas a que hagan suya la creatividad propia de los niños y la espontaneidad de los pueblos primitivos. Al igual que los movimientos anteriores, el grupo fue desde sus inicios enormemente crítico con el surrealismo, tanto es así que, en una carta a Jorn, Dotremont advertía de los tres peligros a los que tenía que enfrentarse el desarrollo autónomo de CoBrA: el surrealismo, el arte abstracto y el realismo socialista. En 1951 CoBrA se disuelve, según Debord «por la falta de rigor ideológico, el aspecto principalmente plástico de sus investigaciones y, sobre todo, por la ausencia de teoría general de las condiciones y de las perspectivas de su experiencia» (Debord 1957: 7).

En 1952 algunos miembros letristas no conformes con las dinámicas de Isou al que acusan de conservador, deciden escindirse y fundar la Internacional Letrista (de ahora en adelante I.L.). Sus integrantes, entre los que se encuentran Guy Debord, Michèle Bernstein y Gil J. Wolman, analizan el panorama francés en los años 50 desde una visión crítica de inspiración marxista y denuncian la ausencia de nuevos movimientos artísticos. Para ellos el surrealismo pierde desde los años 30 su carga innovadora hasta llegar a su completa asimilación, esto es, al entrar en los templos de arte burgués: museos y galerías, y en la publicidad. El proceso de destrucción de los valores formales que se inicia con Baudelaire finaliza con Joyce y Malevich: desde entonces toda escritura o toda pintura abstracta solo pretende abrir puertas que ya están abiertas. Por esta razón, los letristas no pretenden crear artefactos culturales inéditos, sino que buscan una verdadera revolución cultural. 


\section{La Internacional Situacionista}

Una sección de la I.L., junto con miembros del grupo CoBrA, del Movimiento por una Bauhaus Imaginista ${ }^{3} \mathrm{y}$ del Comité Psicogeográfico de Londres ${ }^{4}$, funda en julio de 1957 en Cosio d'Arroscia la Internacional Situacionista (I.S. a partir de ahora), que, dada su composición, se alza como una síntesis de los movimientos anteriores. Entre sus miembros fundadores están Debord, Berstein, Gallizio, Jorn, Olmo, Simondo, Verrone y Rumney, a los que se unirán más tarde Constant y Raoul Vaneigem entre otros. Parten de un diagnóstico común sobre la situación de Europa: creen que el letargo de la posguerra está llegando a su fin y albergan la esperanza de que los acontecimientos sucedidos en Argelia el año anterior y las revueltas de Polonia y Hungría puedan ser un verdadero ciclo revolucionario. Están de acuerdo en la importancia de la cultura para la creación de una nueva sociedad, en el papel fundamental de las innovaciones tecnológicas, en la necesidad de un trabajo colectivo y en la pretensión de desterrar el concepto de artista burgués y su viejo arte reificado (casi todos sus miembros habían militado en distintas organizaciones y partidos políticos). Todas estas líneas de fuerza convergen al servicio de un objetivo: superar el vacío cultural presente y terminar con la escisión entre arte y vida, esto es, abolir esa separación entre ambas para que el arte se pueda realizar en la cotidianidad.

Para ello la I.S. llevará a cabo propuestas muy creativas, generalmente en los márgenes del arte. Marcadas por el experimentalismo, estas propuestas fusionan técnicas provenientes de las distintas artes visuales y disciplinas no artísticas, desde la geografía hasta la psicología, puesto que la superación del arte exige necesariamente la disolución de los géneros en los que se ha constituido. La construcción de situaciones, el détournement, el urbanismo unitario o la psicogeografía y sus dérives representan sus mayores hallazgos.

Guy Debord redacta en 1957 el documento fundacional, «Informe sobre la construcción de situaciones y sobre las condiciones de organización y la acción de la tendencia situacionista internacional». En él reflexiona sobre el estado de la cultura moderna en París, que sigue siendo junto con Moscú la capital de mayor influencia cultural en los países de la zona capitalista. En París la ideología hegemónica burguesa, haciendo uso de mecanismos comerciales, consigue dominar la actividad cultural y banalizar los descubrimientos vanguardistas para difundirlos una vez esterilizados. Perdura la moda del surrealismo, la cual, dirá Debord «tiene todos los sabores de la época surrealista y ninguna de sus ideas. La repetición es su estética» (Debord 1957: 4). Junto a este triunfa la literatura existencialista que, desde su óptica, reproduce bajo el envoltorio de una supuesta filosofía, los mismos aspectos mediocres ya presentes en las décadas anteriores y consigue mantener el interés a base de falsificaciones del marxismo y del psicoanálisis. Del otro lado, en los «estados obreros», se desarrolla en la escritura un realismo socialista que a su modo de

${ }^{3}$ El MIBI fue fundado por Asger Jorn con el objetivo de acercar los límites de la pintura a la arquitectura y el diseño urbano. Más tarde se sumará quien será su aliado incondicional, Giuseppe Pinot-Gallizio.

${ }_{4}$ El Comité Psicogeográfico de Londres está representado principalmente por Ralph Rumney. 
ver no hace otra cosa que mantener los valores del pasado y salva únicamente la experiencia iniciada por Bertolt Brecht en Berlín.

La idea nuclear de la I.S. es la «construcción de situaciones» y de ahí su nombre. Gran parte de su labor teórica y de sus prácticas artísticas tratan de desarrollar de manera amplificada este concepto. La I.S. da una definición en el número uno de la revista «Internationale Situationniste»: «momento de la vida construido concreta y deliberadamente para la organización colectiva de un ambiente unitario y de un juego de acontecimientos»». Con la creación de situaciones, que incluye el más amplio abanico de acciones, intervenciones, proyectos y momentos, buscan inventar nuevas leyes entre los objetos o mostrar sus relaciones ocultas para construir una nueva cultura, un nuevo arte. Para construir, dicen, es necesaria la destrucción moderna de la noción de espectáculo, pues el principio mismo del espectáculo está ligado a la alienación del viejo mundo: la no-intervención. Lo cual no conlleva, aunque así pueda entenderse, arrasar con todo el arte realizado hasta el momento y comenzar desde el principio, sino más bien generar nuevos sentidos, nuevas formas de comprender la realidad y de vivir a partir de los elementos existentes. «No debemos rechazar la cultura moderna sino apropiárnosla para negarla», afirma Debord en este manifiesto programático. Un ejemplo de esta apropiación es el uso que hicieron del détournement. Niegan la creación como la conciliación saussuriana entre forma y contenido y, aunque entienden que el criterio de novedad y de investigación formal ha perdido su sentido desde Joyce, en realidad, procuraron siempre emplear nuevas formas para distanciarse de las ya asumidas por la cultura dominante.

En esa constante búsqueda apuestan por un arte que comprenda todas las disciplinas y que se aleje de la división clásica de las artes y los géneros. Entienden que este arte integral no puede realizarse más que al nivel de urbanismo, por ello proponen el concepto de urbanismo unitario ${ }^{5}$, al que definen como una composición integral del medio en la que concurren un conjunto de artes y técnicas. Se trata de una teoría que rechaza la lógica utilitarista de la sociedad de consumo y busca la realización de una ciudad dinámica donde la libertad y el juego, entendido como no competitivo e integrado en la vida corriente, ocupen un lugar central. La concepción es más extensa de lo que abarcaba la arquitectura, pues el urbanismo unitario, según su formulación, tendrá que dominar desde el medio sonoro, hasta la distribución de bebidas y alimentos. Para su realización hay que crear estructuras nuevas e invertir las formas conocidas de la arquitectura, el urbanismo, la poesía o el cine. Se autodefine sobre todo en oposición al funcionalismo: «los arquitectos funcionalistas construyen cementerios de hormigón armado donde grandes masas de población son condenadas a aburrirse hasta la muerte», afirma Constant en «Otra ciudad para la vida» ( 1959: 1). Apoyado en estas ideas, el artista holandés desarrolla su ambicioso y conocido proyecto de Ciudad cubierta, Nueva Babilonia, un espacio colectivo suspendido en el aire sobre toda la amplitud de una población que presenta la posibilidad de renovarse y transformarse periódicamente de la mano de sus habitantes.

\footnotetext{
5 Stewart Home en Asalto a la cultura afirma que es Constant quien desarrolla este concepto. No obstante, el mérito inicial se debe a una idea embrionaria de Ivan Chtcheglov, miembro de la I.L.
} 
Este proyecto se encuentra muy ligado al contexto histórico posterior a la Segunda Guerra Mundial, pues tras la destrucción de varias poblaciones europeas, de núcleos civiles y de parte del patrimonio cultural, los artistas sienten la necesidad de construir un mundo diferente sobre los restos de esa devastada Europa.

El interés por el urbanismo proviene en parte de los estudios que los letristas habían englobado bajo el término de psicogeografía con el que designan la observación de los efectos que los diversos ambientes urbanos producen en el estado de ánimo y en el comportamiento afectivo de los individuos. Esta disciplina, que fue anticipada por las observaciones de Gilles Ivain en el seno de la I.L., se desarrolla a partir de las indagaciones de Abdelhafid Khatib, quien realiza una descripción psicogeográfica del barrio parisino de Les Halles. Estas exploraciones se llevan a cabo mediante dérives. Las definen como «una técnica de paso rápido a través de ambientes variados»: paseos de aproximadamente una jornada de duración dejándose llevar por los requerimientos del terreno y de los encuentros. Aunque es cercano al concepto de deriva surrealista, los situacionistas remarcan que su deambular no es meramente arbitrario, como sería el de los primeros, sino que refleja una situación objetiva de interés o de aburrimiento. Encuentran en el laberinto la estructura espacial más estimulante y de ahí su interés por ciudades como Venecia o Ámsterdam. El fundamento de este instrumento es tratar de superar la geometría euclidiana que da pie a una visión exclusivamente cuantitativa del espacio.

A pesar de la valía de las innovaciones de los situacionistas, el movimiento ha quedado relegado a un segundo plano y se le ha prestado más atención desde la teoría crítica del valor marxista, aun con la falta de rigurosidad de sus tesis, que desde la teoría y crítica literaria y artística, con algunas excepciones como los trabajos de Debord, las pinturas de CoBrA dentro del movimiento expresionista figurativo o los proyectos urbanísticos de Constant. Su trascendencia posterior llega de la influencia -discutida por distintos académicos- en el Mayo del 68. Para José Luis Pardo, en el prólogo a la Sociedad del Espectáculo, los situacionistas fueron sin duda el germen de esa revuelta:

Poco a poco vamos comprendiendo mejor que aquel escenario que entonces, inesperadamente, inundó las miradas desconcertadas de los viandantes como un signo venido de otro mundo, había sido cuidadosamente preparado por un grupo de disidentes malditos y marginales que llevaban más de quince años conspirando para ese momento, agazapados en la oscuridad y con los ojos y oídos bien abiertos, aguardando la señal. Eran los situacionistas. (Debord 2010: 10)

Si los situacionistas se ubican en el margen, como afirma J.L. Pardo, entonces, cabe preguntarse ¿quién ocupa el espacio artístico y literario en el contexto francés durante los años cincuenta?

\section{La ocupación del centro}

En el mismo escenario en el que se desarrolla la I.S. comienza a surgir otra serie de movimientos nouveaux que pretenden igualmente liberar a la cultura francesa de 
finales de los años cincuenta de las rígidas estructuras heredadas que pautan la creación artística. Entre ellos, el Nouveau Roman, la Nouvelle Vague o la Nouvelle Critique plantean nuevas poéticas narrativas y una profunda renovación en la metodología y análisis de textos literarios. Proponen mirar desde un lugar más coherente con la visión y la ideología del hombre de la época, que no es ya el mismo que era antes de la guerra. Estas corrientes copan la atención de la academia (más tarde formarán parte de ella) y ostentan el privilegio de la palabra en los medios de comunicación de masas, especialmente en el transcurso de los años sesenta.

Ambas fuerzas, los nouveaux y la I.S., pugnan por colocarse en el centro del panorama artístico desde donde irradiar sus convicciones estéticas, pero para llegar ahí lo hacen por distintos caminos: los primeros emplean la vía académica y todos los sistemas subsidiarios de difusión; los segundos se sitúan en la periferia y tratan de filtrarse en los huecos vacíos que deja el sistema institucional. Como es de esperar, los situacionistas dirigen sus críticas a estos movimientos nouveaux y los acusan de ser una continuación del arte burgués alienado. Observan en ellos un deseo de reconocimiento individual y de inclusión en el canon como el que puede extraerse del enunciado que pronunciara Jean-Luc Godard en "Cahiers du Cinéma»: «Hemos ganado haciendo admitir el principio de que una película de Hitchcock, por ejemplo, es igual de importante que un libro de Aragon. Gracias a nosotros, los autores de películas han entrado definitivamente en la historia del arte» (1959). Por el contrario, los situacionistas aspiran a la acción colectiva con el fin de abolir los obsoletos privilegios del artista y devolver el arte al pueblo. Al mismo tiempo, rechazan esa búsqueda de legitimación institucional implícita en el enunciado de Godard pues la propia acción de legitimar conlleva el mantenimiento de una estructura jerárquica y de un sistema de valores capitalista donde el arte se conforma como una mercancía más en su valor de cambio. La I.S. cuestiona la base de sus planteamientos, de raíz estructuralista, al encontrar incongruente la pretensión de subvertir el orden cultural hegemónico desde y para posiciones precisamente hegemónicas y burguesas.

Una de las polémicas más productivas de la época la protagonizan con los autores del Nouveau Roman. Esta escuela, que nunca se definió a sí misma como tal, estuvo formada por una serie de novelistas en torno a la Editorial Minuit, en cuya nómina suelen incluirse Alain Robbe-Grillet, Michel Butor, Claude Simon, Claude Ollier, Jean Ricardou, Robert Pinget, las primeras novelas de Nathalie Sarraute y Marguerite Duras. Todos ellos trabajan en una misma dirección: subvertir las estructuras narrativas heredadas que sentían ajenas a los nuevos tiempos que les había tocado vivir. Para algunos académicos esta escuela constituyó -y constituye- el último intento decididamente innovador frente a la progresiva expansión del interés por retomar la trama en la novela. El interés por la «historia» (en el sentido de la «fábula» aristotélica) está motivado -y en muchas ocasiones exigido- por la inclusión de la novela en el sistema de consumo de masas que se está desarrollando de manera imparable en la década de los cincuenta. Los autores del Nouveau Roman, preocupados por la declinación de la experimentación formal, pretenden ser una alternativa a la anterior literatura de Jean Paul Sartre o de Albert Camus, tanto en la técnica narrativa como en la elección del contenido. Reaccionan frente a esta concepción 
existencialista: «el mundo no es significativo ni absurdo; es simplemente», dirá Robbe-Grillet. Para los situacionistas esta elección formal «que simplemente postula la contemplación de lo escrito en sí mismo», afirma Debord en La sociedad del espectáculo, implica la preservación del espectáculo cuya función es «hacer olvidar la historia mediante la cultura». Además, estos planteamientos de subversión narrativa siguen apegados a la dialéctica «afirmación-negación» en la que se suceden los movimientos artísticos y no consiguen realmente trascender los límites de la reflexión y práctica literaria para llegar a la vida cotidiana, único punto de partida para el nuevo arte.

Otra de las controversias iniciadas por la I.S. contra esta «escuela neoliteraria» gira en torno al término «vanguardia», adjetivo que ambas se atribuyen a sí mismas. Entran en una lógica prospectiva y tratan de medir el alcance de sus innovaciones creadoras; saben bien, por la experiencia de las vanguardias históricas, que las creaciones triunfadoras podrían definir la tendencia futura en las artes.

Por un lado, los situacionistas se lamentan de que los teóricos contemporáneos reflexionen sobre la creación literaria vanguardista e ignoren que el rechazo a la literatura y la destrucción de la escritura fue la primera tendencia en las investigaciones de vanguardia en Europa. Se sorprenden de que críticos como Lucien Goldmann incluya a Ionesco, Beckett, Sarraute, Adamov, Duras o Robbe-Grillet como «grandes escritores de vanguardia», pues el propio hecho de nominarlos como «grandes escritores» ya se aleja de la noción misma de vanguardia.

La I.S. parecía negarse a conceder el título de vanguardia a todos aquellos que demostraban su incapacidad de vincular la actividad artística al proyecto revolucionario que, casi por definición, caracteriza a la vanguardia. Goldmann, en cambio, hablaba sin problemas de una «vanguardia de la ausencia», de una vanguardia vacía de valores con los que realizar una crítica constructiva y revolucionaria de la sociedad que rechazaban. Es más, incluso llegaba a identificar la vanguardia en su conjunto con esta ausencia de valores revolucionarios. (Aparicio Mourelo 2003: 237-238)

Por otro lado, Alain Robbe-Grillet, quien ha sido presentado por la academia como el principal representante del Nouveau Roman por su labor teórica, emplea el término «vanguardia» con unos matices diferentes:

Desde el momento en que un escritor renuncia a las fórmulas acostumbradas para intentar forjar su propia escritura, ve pronto que se le adosa la etiqueta: «vanguardia». En principio, eso solo significa que está un poco adelantado a su época y que dicha escritura será utilizada el día de mañana por el grueso de la tropa. Pero de hecho el lector, advertido por un guiño, piensa pronto en algunos jóvenes hirsutos que van, con sonrisa irónica, a colocar petardos bajo los sillones de la Academia, con el único fin de hacer ruido o de pasmar a los burgueses. (Robbe-Grillet 2010: 56)

La atribución del adjetivo «vanguardista» parece, sin duda, una cuestión de óptica y de grado entre dos ejes: uno el de los creadores, y otro el de la crítica, donde entran, a su vez, las variables de mayor a menor conservadurismo/experimentalismo, y de mayor a menor estatismo/sentido revolucionario. En cualquier caso, en la 
actualidad académica el Nouveau Roman no ha conseguido constituirse como una escuela de vanguardia y las obras situacionistas tampoco han logrado el colapso anhelado como argumenta J. L. Pardo:

Sus productos quedan [los de la vanguardia situacionista], como el paisaje después de una batalla, a modo de restos de una guerra fallida que han perdido su razón de ser y que se perpetúan, insólitamente conservados, en aquella esfera cultural separada (los museos, las galerías, las colecciones y, en definitiva, la institución del arte) que ellos habían nacido precisamente para destruir. (Debord 2010: 17)

La propia reflexión sobre la labor de los situacionistas constituye su propio fracaso, pues precisamente cualquier labor hermenéutica, cualquier interpretación sobre su arte implica necesariamente que ese arte no ha sido realizado en la vida, ya que de ser así se habría confundido con ella y sus huellas habrían desaparecido. A pesar de su afán subversivo, su obras se han vuelto legibles, teorizables. A pesar de su lucha constante su arte se ha convertido en espectáculo, en mercancía intercambiable desprovista de todo poder transformador.

\section{Referencias bibliográficas}

APARICIO Mourelo, Alberto (2003): Construir una pequeña situación sin futuro: la internacional situacionista. De la liquidación del arte a la crítica revolucionaria de la vida cotidiana. Madrid: UCM.

CALVo SerRaller, Francisco (2001). El arte contemporáneo. Madrid: Taurus.

CROW, Thomas (2001): El esplendor de los sesenta. Madrid: AKAL.

DEBORD, Guy (1957): Informe sobre la construcción de situaciones y sobre las condiciones de la organización y de la acción de la tendencia situacionista internacional. Fuera de banda, 4, 12.

DeBorD, Guy (2010): La sociedad del espectáculo. Valencia: Pre-Textos.

Debord, Guy \& Wolman, Gil J. (1955): ¿Por qué el letrismo? Potlatch, 22.

Debord, Guy \& Wolman, Gil J (1956): Métodos de la Détournement. Les Levres Nues, 8.

GARCíA MURILLO, Ricardo (2005): Sujeto y realidad objetual: Alain Robbe-Grillet. Thémata. Revista de filosofia, (35), 541-548.

Home, Stewart (2004): El asalto a la cultura. Barcelona: Virus.

INTERNACIONAL SitUACIONISTA (1963): La vanguardia de presencia. Internationale Situationniste, 8.

JAPPE, Anselm (1998): Guy Debord. Barcelona: Anagrama.

NIEUWENHUYS, Constant (1959): Otra ciudad para otra vida. Internationale Situationniste, 3.

PERniola, Mario (2010): Los situacionistas. Historia crítica de la última vanguardia del siglo XX. Madrid: Acuarela \& A.Machado.

RobBe-Grillet, Alain (2010): Por una nueva novela. Buenos Aires: Cactus.

ROJAS, Waldo (2012): Cronología del movimiento surrealista. Santiago de Chile: UC.

STONOR SAUNDERS, Frances (2013): La CIA y la guerra fría cultural. Debate. 